\title{
Curating actor-network theory: testing object-oriented sociology in the Science Museum
}

\author{
Laurie Waller* Technische Universität München
}

\begin{abstract}
Across different traditions of social research, the study of science exhibitions has often taken the form of an 'object-oriented' inquiry. In this tradition, actor-network theory (ANT) has focused on how the processes of exhibiting objects mediate relations between science and society. Although ANT has not developed as a theory of curating, it nonetheless contributes to revaluing the work performed by curators in relation to the practice of science. This article describes an ethnographic engagement with a curatorial experiment in a science museum which staged a 'multi-viewpoint' exhibition of an object. A display of an object 'in process', I take the opportunity of this curatorial experiment to explore analogies drawn in ANT studies between museums and laboratories in attending to the ways that curatorial practices mediate science. I ask whether, and to what extent, ANT can account for curating as a material practice that not only participates in domesticating objects for science but also in problematizing, multiplying and redistributing relations between objects and the social.
\end{abstract}

Key words: actor-network theory, sociology, science studies, curating, objects.

\section{Introduction}

'There isn't much science in the Science Museum'. This phrase was both a frequent complaint I heard when talking to people about the ethnographic study I was conducting at London's Science Museum, and a regular trope in light-hearted discussion with the curators I was following. If its task were the representation of the vast gamut of 'the sciences', it is perhaps not unsurprising that the Science Museum would invariably fail to deliver. How could one museum possibly deliver such a feat of representation as to capture the whole body of changing knowledges, practices and problems of the sciences? From such a standpoint, the Science Museum would indeed appear rather provincial: the objects it exhibits come mostly from collections dominated by industrial history and medicine, and its interactive exhibitions often engage visitors not in pure science but with complex socio-technical problems. The Science Museum has often been said, not least by its curators (Morris 2010), to convey a historically specific idea of science which derives, in part, from its earlier history as a museum managed by a department of state. But science in this setting has many other attachments too. Walking to the Museum it was impossible not to notice the queues of tourists that gather on Exhibition Road and I was continually reminded that the exhibition of science was not confined only to the galleries inside this austere building: as a tourist attraction, the exhibitions of the Science Museum also circulate globally and bring together actors from across many varied and changing societies. Despite representing an institution that speaks in the name of Science, I was surprised at how few of the curators I met during my study seemed invested with normative, demarcationist, views of science as a rational enterprise inhabiting an irrational social world. Their bookshelves were filled with publications from across sociology, cultural studies, science studies, social history and they often seemed to have more expertise in social theory than I held, as a visiting sociology $\mathrm{PhD}$ student. And yet, there seemed a strange agnosticism among the curators, at least in their conversations with me, about how big theories of science related to the name of the setting 
where they worked. If the Science Museum is a setting in which relations between science and society are curated, the curators often seemed rather reluctant to consider themselves spokespersons for Science.

This article takes the occasion of a curatorial experiment at London's Science Museum to open up the question of the relations between curating and 'object-oriented' sociology, with a specific focus on actor-network theory (ANT). ANT has long been deployed in both sociology and social studies of museum (for instance, Hetherington 1999), often under the rubric of a material 'turn' in social research which shifts the analytical focus of object-oriented research from the study of 'products' to the 'processes' through which objects materialize in social practice (this ANT argument is most directly made in Latour 1988). ANT is particularly pertinent when considering the practice of curating in science museums, which across various traditions of social research have long been characterized as institutions that exhibit the most domesticated scientific products. In what might be called 'product' theories, science museums are located at the far end of object trajectories that begin with practices of the sciences and which lead to the circulation of new facts and artefacts in society. In such theories the science museum is marked by its distance not only from the practices of science but also from processes through which new things emerge in societies. Science museums in this product model are conservationist in orientation and curatorial activity is assumed to be the concern of maintaining established settlements between science and society, whether through education, interactive display or cultural initiatives. Product theories of the science museum are widely associated with particular schools of social criticism: for instance, that the science museum represents the world instrumentalized and objectified, or conversely, that the science museum is the materialization and protection of reason against the irrational forces in societies. Product theories might be said to be widely found in sociological traditions such as interactionism which treats the products of science as those things domesticated as the furniture of social life and in positivism for which scientific objects constitute the very reality of social associations. The product theory of the science museum, in this sense, might be said to hold a long-standing position within the discipline of sociology.

By contrast, ANT studies suggest that science museums do not only occupy the end point of the social trajectory of a scientific object but rather are settings where the relations between science and society are materially tested and ordered in curatorial practice. ANT proposes that objects of the kind we find in science museums are rarely as neat and closed as product theories suggest. Rather than 'products', then, ANT therefore suggests that scientific objects are better understood as 'quasi-objects'" . ANT argues that the material strength of an object is not pre-determined before it enters society but is rather subjected to continual testing as it circulates in different social settings. Scientific objects might appear as closed products when they are socially stabilized but are better understood, according to ANT, as long chains of socio-material relations that cut across science and society. For ANT, scientific objects do not simply arrive in society from nowhere but are rather made social through the work of 'mediators', actors that operate in between science and society to produce relations between them. The representation of a scientific object is always, in ANT, an act of its mediation. What kind of mediators, then, are science curators?

In what follows I discuss a curatorial experiment that I followed as a participant-observer. In this experiment a variety of groups participated in curating a 'multi-viewpoint' exhibition of an object. The Science Museum's professional curators did not use the language of ANT to describe this experiment, although they certainly were not unfamiliar with it. However, the multi-viewpoint exhibition seemed to me, in many ways, to stage a distinctly ANT-like display: offering a processual view of the object and foregrounding its mediations by heterogeneous actors. In this article, I use the occasion of this curatorial experiment to explore ANT's account of scientific objects and ask how objects are mediated in the process of curating exhibitions. The article first introduces the curatorial experiment and its object, a recently rediscovered synthesizer, and I discuss some of the particular ways in which the synthesizer was mediated in the curatorial experiment. Specifically, I argue that this experiment served to problematize the work of curating, to multiply the participants who might be considered mediators, and to redistribute the work of curating science. In the following section I discuss ANT's account of the science exhibition. Specifically, I attend to two related claims of ANT: first, that objects are 
never univocally scientific but are always 'quasi-objects' - complex mixtures of science and society - and, second, an exhibition can be understood as a 'test' of an object that is necessary for it to be accommodated in the common world. In the following discussion I engage with the proposition made in some ANT-studies to draw an analogy between the laboratory and the museum, as equally social settings that participate in the material production of science. In concluding, I question to what extent such analogies might be said to contribute to revaluing curatorial work as material practice and propose opening up the question of the ways in which exhibitions participate in socially domesticating scientific objects.

\section{The multi-viewpoint exhibition}

As an ethnographer, I followed the work of curators at London's Science Museum as they experimented with developing what they would regularly refer to as a 'multi-viewpoint exhibition'. The object of the exhibition was a recently rediscovered electronic music synthesizer built in the early 1960s by the composer Daphne Oram (1925-2003): the Oramics Machine. Although the Oramics Machine appeared far from a conventional scientific product, the Machine was not 'un-technical' and was, for instance, described by some participants as an example of early computation techniques in electronic music (Grierson \& Boon 2013). In preparing the multi-viewpoint exhibition, the curators at the Science Museum had conducted a series of experiments using participatory procedures which they called 'co-curation' ${ }^{2}$ techniques, and through which groups with a variety of social identities, technical competencies, knowledges and practical experiences of electronic music were invited to contribute material for the gallery display of the Oramics Machine. The Museum's curators included historical researchers and museum participation specialists and were using the curatorial experiment both as a method for inquiring about what they termed 'public history', concerned with the different kinds knowledge about the history of science and technology held by non-experts, and with the development of new forms of participation in the museum. The multi-viewpoint exhibition was thus an event which appeared 'multiple' even in the curators' own accounts of it.

Curatorial experiments, particularly in science museums, have often taken place 'behind the scenes' (MacDonald 2002), where controversies are hidden from the public view. But such front-stage/back-stage boundaries were considerably blurred in the case of the curatorial experiment discussed here. Indeed, in many instances it appeared that maximum publicity was a central pillar of the Science Museum curators' approaches to experiment, multiplying the ways in which the experiment was publicized and mediated. At each end of the gallery display, for instance, text graphics informed visitors that the exhibition they were about to visit was experimental in character. In the gallery, a film staged an interview with one of the curators describing the curatorial approach taken, and the groups that participated in curating the exhibition's displays. In the film, the curator elaborates the process:

The Oramics exhibition is the first exhibition in the Public History Project and we're planning two others. Co-curation, participation, co-creation; [this approach is] not having the curator saying "here is the gospel come and read it" but instead bringing in people like our visitors to work on the development of the Museum's cultural offer.

As the curator speaks, the films shows a group of people standing around the Oramics Machine peering with intrigue at its various component parts and discussing its place in electronic music history. In various parts of the film, participants offer their reflections on the curatorial process, and I am even featured in the film as a participant with one of the co-curating groups; as a participant-observer, my relation to the curatorial experiment was also complicated by the multi-viewpoint staging of this exhibition ${ }^{3}$. Making visible both the curators and presenting the Oramics Machine in the process of being prepared for public display, the gallery display appeared to unsettle distinctions between exhibition procedures and products that have often framed practices of curatorial experiment.

Science museum galleries have often provided settings for experimental exhibitions: having been widely used as the stages on which experimental instruments, techniques and findings are publicised (Hooper-Greenhil 1992) ${ }^{4}$; they have also served as the end point of 
the development of experimental curatorial procedures in science museums (MacDonald 2002); and, galleries have also provided the controlled settings in which experiments can be conducted in public (Weibel \& Latour 2007). Arguably, all three versions of the experimental exhibition were present in the case discussed here. The Oramics Machine was an experimental instrument in multiple senses, but perhaps most notably as a musical instrument. The gallery also clearly provided the end point for the experimental "co-curating procedures trialled by the Museum's professional curators. And, the experimental gallery display was also publicized as such to those visiting it. The multi-viewpoint gallery display might therefore be said to have been multivalent as an experimental science exhibition, enacting multiple versions of what was experimental about the exhibition and the settings where the experiment was happening.

At the centre of the gallery, the Oramics Machine seemed far from an arbitrary choice for the experiment. Although its inventor, Daphne Oram, had founded the first public electronic music studio in the UK - the Radiophonic Workshop at the BBC, which she left shortly after it opened - she had much less subsequent success in demonstrating the Oramics Machine as an innovation in electronic music. Oram realized only a handful of compositions on the Oramics Machine, which effectively never left her home-studio. Until its rediscovery, there were almost no publicly available recordings of the Oramics Machine and less than a handful of books about the history of electronic music had mentioned it, most of which were authored by close associates of Daphne Oram. Media coverage for the exhibition further dramatised the Machine's alterity from the world of scientific products foregrounding the fact that the Oramics Machine was rediscovered rusting in a barn in rural France. After a complicated conservation process, the pieces of the Oramics Machine on display comprised a coherent assemblage, though one still distant from a completed product: the frame of the Machine assembled from repurposed metal shelving, a wooden cabinet housing one part of the machine was for most of the exhibition labelled 'commode', and a broom handle was conspicuously jammed in one side of the Machine. On one side of its exhibition case a text label stated that the Oramics Machine would never again work and this seemed corroborated by the plethora of colourful wires that hung unconnected from the Machine's body, surrounded by open circuitry still exposed and corroded, and a switch which appeared alongside a handwritten label: 'do not switch'. Somewhere between unattainable aspiration and laboured materialization, the rediscovered Oramics Machine seemed less the revival of forgotten innovation and more the recovery of something distinctly incomplete, still 'in process'.

The curators made no secret of their delight at the Oramics Machine. In a video accompanying the Oramics Machine's gallery display, one curator enthused:

The discovery of the Oramics Machine has been one of those great events in a curator's working career. It's a real bit of home brew. Just by looking at it you can tell that it was always work in progress, that it was always being modified, and it's unique. Daphne Oram is an absolute gift to an exhibition-maker.

The curator's enthusiastic description of the Oramics Machine seemed to revel in its 'nonproduct' status. The Machine is in quite a literal sense 'home brew', having been constructed in Oram's home-studio: a converted oast house in rural Kent. The curator's narration of the Machine here is perhaps notable for the ease with which they shift between the object, the context of its invention (Oram's home) and to the inventor herself. Such 'shiftiness' I found was apparent throughout the exhibition, not least in one of the main publicity images which showed Oram composing with the Machine in her home, drawing wavy lines onto strips of film that run across its surface: foregrounding neither composer, machine or the domestic context but rather staging their relations, such publicity offered distinctly opaque and unconventional images musical practice and technological operation.

Right from the start of the ethnographic study, when I found myself following one of the curators to an experimental music venue on the opposite side of London to the Science Museum where one of the curators presented the proposal for the curatorial experiment and exhibition, it seemed clear that the Oramics Machine afforded the possibility of taking curatorial practice 'outside' the museum site. In between presentations about the Oramics Machine by a computer scientist, a sonic artist and a music journalist, the curator discussed the acquisition of the object and invited the assembled crowd to participate in the experiment. 
Although at this early stage in the ethnography l'd been principally following the work of the curators at the main site of the Science Museum, in South Kensington, this event seemed to demonstrate the way in which the Oramics Machine might also afford the exhibition of the curatorial experiment in other sites.

During the experiment I was invited to become participant in a group of musicians to select different inventions from electronic music history for a case display. Discussions about the Oramics Machine during this process often concerned the Machine's relation to other DIY musical instruments, early synthesizers and the broader ethic, common to much experimental art, of working with material constraints. While the co-curating sessions took place in the Science Museum and the gallery, it was striking that many members of this group seemed actively engaged in the work of multiplying the media of the curatorial experiment: for instance, several of the participants blogged during the various stages of the process, one member of the group did a radio show about it, another produced a subsequent exhibition of materials from Daphne Oram's archive, one member published a magazine article on the exhibition, a few participants in the group lent and even built instruments for the exhibition, and others used their social media accounts to publicise the opening of the exhibition. The work of the 'co-curators' appeared to mediate the Science Museum's exhibition of the Oramics Machine such that it was happening in multiple sites, many of which were distinctly removed from the gallery display in South Kensington.

By contrast with the group of musicians, when I interviewed members of other groups involved in curatorial experiment, the Oramics Machine seemed mediated as something quite different. One striking example was the staging of a series of texts in the gallery by anonymized 'women writers' 5 . In an interview, a creative writer who had been contracted by the Museum to run workshops with a group of writers described to me how the process had focused not specifically on the Oramics Machine but on Daphne Oram and on broader questions of sonic invention. In fact, in the women writers' texts almost no references appeared to the Oramics Machine as musical instrument, and instead the texts seemed to present the Oramics Machine by proxy through the lived experience of its inventor Daphne Oram and references to the home-studio environment in which she worked to create new sounds. In the Science Museum's gallery display, questions of gender and exclusion were quite literally dramatised in the presentation of the texts as recorded audio performances of monologues, each narrating personal experiences through a lone female voice. These displays seemed to mediate the Oramics Machine as a 'social' object that both dramatised what has been called the 'woman question in science' (Harding 1986) while also performing a particular kind 'cultural inclusion' that has been common to both science and the museums.

Yet another mediation of the Oramics Machine could be found in an interactive application designed by computer scientists at Goldsmiths College London, who had worked with the Science Museum's curators to acquire the Oramics Machine. In interviews I conducted with these researchers, the discussion centred on the electro-mechanical design of the Oramics Machine and questions about the relation of the Oramics Machine to developments in voltage controlled sound-synthesis. I later visited one of the researchers at their studio as they were building a prototype of a 'mini' version of the Oramics Machine that Oram had developed plans for but never realized. The researcher went on to demonstrate this in various locations that included academic seminars, experimental music venues and concert halls. Research on the Oramics Machine as a computing machine was not taking place in a traditional engineering institution but rather between the Science Museum's conservation labs where the Oramics Machine was being restored, the arts college where Oram's archive was held, the studio, and music performance venues.

Finally, in discussions with the Science Museum's curators about the significance of the Oramics Machine there seemed to be a refusal on their part to instrumentalize the Oramics Machine as an object for publicizing a 'complete' science. An email discussion with one of the curators involved offers one such instance:

Was the Oramics Machine important as an invention? Maybe not, but it is important in the sense that it says so much about the inventiveness and creative minds that were involved in electronic music in those early years. And it's a nice 
counterbalance for the idea that it's a masculine story involving knobs, dials and an emotionless process. I think museums should talk about dead-ends quirks and failures a lot more. They are part of the history of Science, Technology, Engineering and Medicine and can help us see the big stories in a different, more diverse and balanced light. (personal communication from a curator, 10/09/2012)

In this example, the curator puts questions about innovation, that have often dominated discussions about science museum objects, to one side in order to talk about their interests in the modes of cultural creativity that developed in 1960s electronic music studios, and in (feminist-inspired) critiques of the gendering of science and technology. Rather than engaging in tired questions about innovation, the curators seemed simply to make a 'redistributive move' to show that such binary questions had actually a much richer life at the intersection of epistemic, technical, cultural and museological problematics.

As an ethnographer I found it impossible to follow all of the ways in which the Oramics Machine was mediated in the multi-viewpoint exhibition. Post-product accounts of science museums, like ANT, impress on the researcher to attend to the ways in which relations between science and society are stabilized and domesticated in these settings. And yet, in following the making of this multi-viewpoint exhibition it seemed that the curators were more concerned with provoking and unsettling the question of the Oramics Machine's relation to science at every opportunity. When I would discuss this with the curators, they would explain to me that the exhibition of the Oramics Machine was extremely peripheral to the mainstream work of the Science Museum: it was poorly funded, developed within an extremely short time frame, and, as one put it, was 'hardly particle physics'. If the Oramics Machine was unsettling relations between science and society, it did little upset the exhibitions about industrial history, technical pedagogy displays and 'hands-on' interactive installations of the contemporary science galleries surrounding it, and for which this Science Museum is well known. The multi-viewpoint exhibition seemed, in some ways, simply an attempt to add one more style of gallery display to the Museum's existing repertoire; to multiply the possible genres of science curating that could be developed in this setting. Indeed, its peripheral character seemed evident as I followed the curators and the participants in the experiment out into a host of settings of practice, distant from those of conventional science. The peripheral character of the curatorial experiment in the Science Museum was, in this boundary-testing sense, precisely why it seemed an interesting test case for ANT theories of science exhibition.

\section{Actor-network theory and the curator as mediator}

Actor-network theory does not have a well-developed account of curating. However, public exhibitions of experiments have occupied a central focus in ANT studies in demonstrating the work of mediating science (Latour 1993b). Public exhibitions of experiments have long been central to the task of demonstrating that facts can be disentangled from the local sites of their production and can circulate in society (see also Shapin \& Schaffer 1985). The experimental exhibition has, in science, therefore often been considered an event that participates in the socialization and domestication of experimental entities. In describing the work of assembling exhibitions as mediating relations between science and society, ANT has, I suggest here, contributed to the revaluing of work of science curating as a practice that does not simply diffuse ready-made facts into society but rather as a process that mediates an experimental entity in a way that could be said to be continuous, rather than radically separate from, laboratory practices of experiment.

Actor-network theory is far from the only critique of 'product' theories of the science museum. Empirical studies have widely described science museums as settings that not only hold the socialized products of science but are also settings where relations between science and society are produced in practices ranging from collaborative research (Star \& Griesemer 1989) to taxidermy (Haraway 1984) to design and advertising (MacDonald 2002). In such studies we find a range of 'non-productized' accounts of the objects found in science museums, including: boundary objects that contribute to the formation of scientific fields (Star \& Griesemer 1989); epistemic objects that order relations between experts and publics (MacDonald \& Silverstone 1992); and artefacts that render social relations as material culture. In none of these 
accounts can the science museum simply be consigned to the end of a continuum between science and society. Rather, by opening the black-box of product theories, empirical studies have shown that science museum can be many things, including: a context for research and site of discipline formation, an arena in which the politics of knowledge is played out, and a location where nature is materialised as culture. By attending to the diversity of object-oriented practices found in science museums, and the social roles that these objects can perform, they highlight the artifice involved in producing relations between science and society. Few of these studies directly deploy ANT, and indeed some of these studies developed important critiques of ANT (for instance, Star \& Griesemer 1989). I focus on ANT here because, in so far as it has been specifically concerned with describing the work of assembling experimental exhibitions, I suggest it can be considered an approach that also participates in revaluing the practice of curating.

The portrait presented here of ANT's accounts of assembling exhibitions is therefore not a complete museum theory of curating, which would include many other practices through which curators care for objects that are less directly related to formal exhibition procedures (although in my experience, the curators carried concerns about display with them even when engaged in other kinds of object practices). In what follows I highlight two key features of ANT studies that distinguish the role of the curator as a mediator that assembles exhibitions and participates in socializing experimental entities. First, ANT argues that scientific objects are never simply as univocal or closed as product theories would propose but are rather 'quasiobjects': complex mixtures of both science and society. The process of exhibiting objects cannot be only an individual or institutional concern, but rather collective and distributed: in processes of exhibition experimenters are obliged to take into account the other actors concerned by the object. Second, ANT argues that experimental exhibitions are not discontinuous with, or radically separated from, the practices of science, but that they are 'tests' of the material strength of a laboratory apparatus. Assembling an experimental apparatus for exhibition is, ANT suggests, a process that 'mobilizes' the apparatus between social spaces and produces socio-material change in the object. In at least these two senses, I suggest, ANT is a theory that proposes a revaluing of curatorial work.

ANT's theory of 'quasi-objects', a concept proposed by the philosopher Michel Serres, concerns the problem of how social actors represent natural things (Latour 1993b). Is it only scientists that can truly represent natural objects, as product theories would suggest? ANT argues that as the sociologist gets closer to the processes of science they can see more clearly that objects are never purely natural. Studying the controversies, disputes, breakdowns and failures in science, ANT studies highlight that the processes through which nature materializes as something objective are thoroughly social. It is only when sociologists are distant from such processes that science and society appear easily separable, and therefore that the representation of objects as univocal natural things might appear uncontroversial (Latour 1988). The theory of the quasi-object is, in this sense, an argument against the notion that science and society comprise ontologically discreet domains within which objects must be positioned. Rather, attending to the quasi-object requires following the processes through which differences between science and society are produced, such as in science exhibitions.

Minimally, we might say that curators are actors that, though processes of assembling exhibitions, make objects speak in the name of science. Where product theories would propose to radically separate practices of exhibiting objects from the processes through which they are made, ANT's quasi-object theory suggests that the work of curating exhibitions in the name of science should not be considered an activity that is discontinuous with the practices of scientists. To limit the work of curating to the 'after-care' process following the successful production of the object would considerably undervalue the role played by curators as not just spokespersons for science but as mediators. ANT's theory of quasi-objects would therefore suggest that curating, as an object-oriented practice, does not take place on one side of a divide between science and society but rather takes place in between these two spheres. The curator, in other words, appears as one mediator who along with many others practically participates in the fabrication of an object. Of course, the curator of exhibitions in science museums is a long way from the laboratory where objects begin their life as experimental 
entities. Nonetheless, curating exhibitions of laboratory inventions can never, in ANT, be considered entirely discontinuous from the experimental apparatuses and practices through which they were produced. The curating of experimental exhibitions does not occur after the end of the experiment but is rather, ANT proposes, a process that mobilizes the experimental apparatus and puts it to material test.

The notion that curating exhibitions might be considered as processes that 'test' an experimental apparatus is, in ANT, linked to the sociological problem of how experimental entities come to be materially stable such that they can circulate in society. Studies of the failure of researchers to domesticate their objects of study have occupied a central place in this broader ANT problematic of describing how scientific objects acquire material strength (Callon 1980; Callon 1986; Latour 1996). More than simply an event in which a completed experiments are communicated and facts diffused in public, ANT has described the exhibition as a test that demonstrates the material strength of the experimental fact; it is an event in which the instruments, devices, procedures - in other words, the whole laboratory apparatus - is submitted to heteronomy (Latour 1993b). In ANT the appearance of experimental facts as knowledge that can exist independent of a material apparatus is an accomplishment of exhibition practices. ANT studies therefore highlight that experimental facts are thoroughly material things but that when demonstrated in exhibitions they acquire a virtual and immutable character that enables their circulation beyond the material setting of their making. The public demonstration is for ANT therefore part of an experimental trajectory through which a fact becomes a social entity. Deploying ANT in accounting for the experimental exhibition is, in this sense, to unsettle accounts of science exhibitions that assume we can clearly separate laboratory work from the work of exhibition or the practice of experiment from the publicity of facts.

ANT conceptualizes the processes through which facts acquire strength and social stability in terms of the materialization of virtual networks of humans and nonhumans. The role of exhibition in this process was given a detailed description in Bruno Latour's (1993a) account of the invention and domestication of microbes by Louis Pasteur. Latour highlights that there was nothing inevitable about the invention of the microbe: the problems which Pasteur's microbiology claimed to address were also the domain of the large French hygiene movement. Pasteur's microbes only became strong, Latour argues, in public exhibitions that demonstrated the microbiology he had developed was not only convincing in the safety of a well-equipped Parisian laboratory but could equally well travel to the sheep farm at Pouillyle-Fort. The provincial spectacle of the isolated rural farmyard, Latour suggests, is crucial to demonstrating to large social groups such as government ministers, the livestock industry and the Society of Agriculture the fact of the microbe. The public exhibition on the sheep farm therefore proposed new alliances of humans and nonhumans to be added to those enrolled in the Paris laboratory testing and increasing the strength of the microbe's network such that Pasteur's vaccination techniques could circulate widely. To accomplish this, Latour argues, Pasteur did not leave his Parisian laboratory behind but rather bought it with him to Pouilly-leFort: in demonstrating the vaccination of sheep he was mobilizing the whole material apparatus implicated in the laboratory experiments. Curating the experimental exhibition was therefore a trial not just of the reality of the microbe but of the extent to which Pasteur's laboratory could travel in all its materiality from Paris to the rural sheep farm. In ANT, then, the curating of experimental exhibitions are processes of assembling networks of humans and nonhumans that comprise a laboratory apparatus, materially testing these relations and participating in their social domestication.

Quite a different ANT account of science exhibition, in comparison to Latour's study of Pasteur, is found in Tony Bennett's (2004) study of Pitt-Rivers's evolutionary exhibition practices. Unlike many ANT studies, Bennett's is not directly concerned with the experimental laboratory sciences. Rather Bennett's discussion of Pitt-Rivers's curatorial practices is situated in relation to the roles played by museums from across the historical sciences (but notably, archaeology, anthropology and natural history) in producing an evolutionary synthesis of natural, geological and human time that could be mobilised within projects of colonial governance and administration. Though Bennett's is a study specifically concerned with the historical sciences, which have not been principally laboratory sciences, it is notable that he nonetheless proposes an analogy between the laboratory and the museum (see also Bennett 2005). Drawing on ANT, Bennett 
argues that the 'black-boxing' of evolutionary time across the historical sciences was, in part, facilitated by curatorial practices of typologically arranging objects such that human cultures could be materially sequenced and demonstrably ordered. The typological display had two main attributes, Bennett argues, that contributed to the black-boxing of evolutionary thought:

First, it made it theoretically possible for all museum collections to be reassembled in accordance with the same principles through the operation of a common grammar across all museum types...the whole of the material world could be lined up and placed before the eyes in a manner which allowed each display to tell its own story, seemingly without the need for textual mediation. It promised a means of making each object auto-intelligible through the place that was arranged for it within an evolutionary sequencing of things that was - to come to the second point - cumulative. (Bennett 2004: 65)

Bennett takes Pitt-Rivers's development of typological techniques for classifying objects as the paradigmatic example. The famous sequential typologies of Pitt-Rivers's ethnological collections entailed, Bennett argues, not only the imposition of cultural order onto a collection of curiosities. It was also a process that made possible the production of relations between people, things and environments as 'cultures' that could be ordered in evolutionary sequences. To appreciate the typological object exhibition as a curatorial accomplishment, Bennett suggests that we cannot simply stay in the museum gallery. Instead, the sociologist must follow the distributed networks of humans and nonhumans, to the far-flung colonial outposts, that facilitated the collection and ordering of these objects as evidence of cultural development. To appreciate the role of exhibition practice in assembling and ordering these distributed networks in typological displays, Bennett invites us to attend to the exhibition as a controlled environment for testing anthropological propositions and as a setting in which anthropology could be materially demonstrated as an evolutionary science. As Bennett's analysis highlights, ANT provides a way to account for how disordered materials - in Bennett's case the jumble of cultural artefacts collected by Pitt Rivers - can be rendered through curatorial practices as stable objects and ordered facts.

In so far as science museums exhibit objects in the name of science, ANT proposes a sociology of curating in which the latter is seen as materially mediating relations between science and society. ANT might therefore be said to have contributed to the current revaluing of the work of curating, demonstrating that the work of assembling exhibitions can be considered to be in particular respects continuous, rather than radically removed from, the practices of science. In this sense, ANT's account of curating might be also said to draw on an older use of the term in the history science to refer to the work of assembling the experimental apparatus for public demonstration. What distinguishes the curator of exhibitions from other mediators of science, in ANT, are the ways in which practices of exhibition involve testing and stabilizing objects, and participates in socially ordering facts. It is only by attending to the work of mediators like curators, ANT argues, that we can appreciate the strength of scientific facts to compel broad social assent.

\section{Museums and laboratories}

ANT's process sociology of curating, as I have rendered it, makes clear that it is not so much the object 'in itself' that is the focus of curatorial practice so much as the apparatus to which it is attached. ANT suggests that in curatorial practice it is not so easy to distinguish the 'hard' from 'soft' aspects of the apparatus; that the object 'in process' of being curated is slippery and difficult to easily separate from the context of the experiment or from the identity of the experimenter. As noted above, in the curatorial experiment I followed, it seemed hard at times to pin down exactly what the object of the experiment was: the Oramics Machine seemed at once a musical instrument, a museum object, an engineered machine, an amateur invention, a studio proto-type. Indeed, the staging of the multi-viewpoint exhibition seemed to make clear the difficulty of cleanly separating the Oramics Machine from the curatorial apparatus or questions about its context in the Science Museum. In many ways, then, the exhibition of the Oramics Machine could be said to enact many of the features of an actor-network theory of curating. 
Debates aboutANT's theory of mediation have highlighted the centrality of the laboratory as the paradigm of material practice of science (Guggenheim 2012; Hess 2013; Latour 1999). Certainly in the case of Pasteur, as described by Latour, the laboratory was central to the curatorial problem of exhibiting the microbe: assembling the exhibition at Pouilly-le-Fort was in Latour's account a problem of mobilizing the laboratory apparatus from Paris to this rural setting. In the context of museum studies, Bennett is not alone in proposing an analogy between the museum and the laboratory (Bennett 2005; Kraeftner et al. 2007; Macdonald \& Basu 2007). One of the key insights of laboratory studies was indeed to highlight the ways in which laboratory settings provide for the practical establishment of multiple viewpoints on experimental objects (Knorr-Cetina 1999; Latour \& Woolgar 1986, Lynch 1985). The Science Museum's curators' staging of the 'multi-viewpoint' exhibition of the Oramics Machine might therefore seem to suggest once more the pertinence of analogies between the museum gallery and the laboratory as settings of experiment. To draw an analogy between the museum and the laboratory would suggest not only that there is continuity between the practices of scientists and science curators but also in the objects with which they are concerned and the apparatuses they develop.

In the conventions of the 'product' sociologies that ANT would purport to critique, the staging of the Oramics Machine as an incomplete object for science would not distract sociological attention from the 'hard' social consequences of the exhibition. Such theories would surely point out the instrumental value of staging the Oramics Machine as an incomplete object for science in accomplishing particular institutional ends: for instance, to stage a culturally inclusive display of science or to demonstrate the museum as an interactive public institution. Though the Oramics Machine may look fragile in the gallery display, product theories might suggest that the object is in fact much 'harder' than it looks. Indeed, such observations would seem not insignificant as insights into the multi-viewpoint exhibition as a social process: the gendered staging of the 'women writers', for instance, could well be said to be a highly opportunist and instrumental staging of cultural inclusion. In this sense, such 'old' sociological materialisms do not appear entirely irrelevant for appreciating the fragile condition of the Oramics Machine or its cultural and public significance in relation to the institutions of science and museology. ANT is surely right about many of the shortcomings of materialist sociologies in failing to adequately account for the processes through which scientific objects acquire their material force, and why a materialist account of science would require sociological attention to the work of curators as mediators. And yet, the seeming relevance of these 'old' sociological materialisms appeared to highlight that if this multi-viewpoint exhibition enacted some aspects of an ANT account of object exhibition it also seemed to unsettle clear distinctions between 'product' and 'process' that form the basis of ANT's object-oriented sociology.

There were many ways in which these tensions between ANT's distinction between product and process could be said to have played out between object, the exhibition and the curatorial apparatus. The exhibition might well have tested the material strength of the Oramics Machine as an object for science, as ANT suggests, but it also seemed hard to imagine that the Oramics Machine might have ever failed given its staging as an object that was never fully realized by its inventor, that never left the studio where it was prototyped and was never demonstrated as an innovation. ANT would suggest that the continuing ambiguity of the Oramics Machine as an object for science might somehow put at risk the identity of the curators exhibiting it or at least stimulate some form of controversy. However, notably few 'science warriors' emerged throughout the duration of my study at the Museum; despite its seeming alterity as an object for science, the Oramics Machine was in many senses distinctly uncontroversial as an exhibition proposition in Science Museum. The exhibition therefore seemed neither a prelude to establishing the Oramics Machine as a univocal scientific object nor a process of 'sorting out' relations between science and society. Neither was it clear that the curatorial apparatus provided the means through which the object acquired material strength and through which distributed relations between science and society were assembled. Certainly, the Oramics Machine has subsequently widely circulated among the different communities of actors concerned with electronic music history and its exhibition often provides a significant point of reference. If the curatorial experiment with the Oramics Machine was a test that participated in the object's socialization, it nonetheless problematized the work of curating, 
multiplied the actors mediating the process, and redistributed the problem of the staging the Oramics Machine in the name of science.

How useful is the laboratory analogy in accounting for such difficulty in distinguishing between 'product' and 'process' accounts of scientific materialism? Does the laboratization of the Science Museum allow that curators might be more than simply mediators that participate in domesticating 'hard' science? Perhaps. But, in many ways the Oramics Machine would seem somewhat strange object to 'laboratize' precisely because its exhibition appears to afford the possibility of curatorial experiment that subverts many of the tropes of institutionalized, pure, and professionalised science. Indeed, the contrary dynamic of 'de-laboratization' (Guggenheim 2012) might provide a perfectly adequate characterization of this exhibition as a staging of science: foregrounding the studio as a setting of invention and celebrating undisciplined technical practices, the aesthetics of machines, and the misuse of instruments.

I suggested earlier that ANT's account of curating science appears to revive an older account of curating from the history of science. This is perhaps instructive for highlighting some limitations of a laboratory-centric model of curatorial practice (e.g. Latour's Pasteur). As Shapin (1988) has highlighted, the curator was a figure that became an expert of experimental demonstration by rehearsing 'at home'. Moreover, for the sake of the experimental apparatus' safety, public demonstrations were, in fact, often conducted in domestic settings. The curator, thus, was a figure whose domestic labour needed to be made invisible for the purposes of putting science on public display. Paradoxically, in the history of science, public demonstrations could be staged as the social 'domestication' of new facts precisely because they were founded on a division of labour that made invisible such domestic work involved in curating experiments (see also Hacking 1983). Treated as a mediator, ANT proposes a 'coming out' for the curator from behind the scenes, as a participant in socio-material processes that produce collectives. Does ANT's revaluation of curating also, then, unsettle this social division of labour between domestic and public spheres? Assembled in Oram's home-studio, there is a certain irony in the domesticated staging of the Oramics Machine precisely because it appears to expose such labour; the household furniture and the broom handle of which it is comprised are particularly obvious signifiers of an approach to invention shaped in many ways by domestic necessity (Waller 2015). To laboratize the curatorial experiment would seem not simply to overlook the pertinence of alternative settings of experiment, such as the studio, but would also seem to repeat a kind of androcentrism by instituting a division of labour in which some forms material practice and androcentrism mediation are valued more than others. If Pasteur's curatorial experiment with the microbe centred on the problem of mobilizing the Parisian laboratory to the rural setting, the exhibition of the Oramics Machine would seem to centre on something of an inversion of this problem: that of mobilizing the home-studio where the Oramics Machine was assembled from the rural setting of Oram's residence in Kent to the Science Museum gallery where it could staged in the name of science.

\section{Conclusion: curating after ANT}

As settings of exhibition, ANT would thus propose that the sociologist approaches science museums not as sites where rationality is defended or institutions that represent the world objectified and instrumentalized, but rather as settings where associations between science and many very different things are materially produced. As I walked around the different galleries of the Science Museum, during this ethnographic study, it was hard not to be impressed by how such heterogeneous instruments, machines, aesthetic styles and cultural events all appeared to somehow 'hang together' in the name of science. The observation that 'there isn't much science in the Science Museum' in this sense seemed less a damning criticism of the institution than an appreciation that assembling so many very different things to speak in the name of Science involves quite considerable artifice. The reluctance of the curators to consider themselves as representatives that speak for science seemed not an obfuscation of a professional duty but rather to acknowledge that the material accomplishment of the Science Museum does not reside in a particular ontology of the objects they hold in collection but rather is assembled in exhibition practices that perform the work of proposing new associations for science. It only takes a brief skim through the Science Museum's corporate literature to find 
the range of associations including national museums, scientific institutions like CERN, and government representatives, but also 'women', 'BME communities', and 'the arts'. ANT offers a neat way of sociologically characterizing the science museum not as simply an institution that represents the sciences but as a setting in which heterogeneous associations of science materialize.

The ANT move from 'products' to the 'processes' was not new to object-oriented sociology; arguably, social research traditions as diverse as social constructivism, Marxism or material culture could all be said to have developed versions of this argument. ANT criticised these other object-oriented sociologies as not being radical enough in applying this move to society itself: arguing that they wrongly maintained society as the object of study for social science when they should have been studying the modes of associative action from which societies emerge (Latour 2005). ANT proposed that sociologists need not to choose between different accounts of social objectivity or ontology but rather to follow the processes through which the social is materially assembled. In attempting to follow the mediations of the Oramics Machine in this curatorial experiment, I have suggested here that ANT might not have renounced commitments to social objectivity or ontology quite as thoroughly as has often be claimed by its advocates. Specifically, if ANT privileges the laboratory as the paradigmatic setting where the material world is mediated, it would therefore seem to propose a benchmark against which the material claims of all other mediators compare. Curators of science are not laboratory scientists but they nonetheless often mediate the same objects and apparatuses: to what extent does the laboratory help analytically distinguish the specific modes of mediation performed by each actor without reintroducing a priori materialist distinctions separating scientific from social work? I've suggested that one way to extend the project of revaluing curating would be to open up the 'domestic' problem in curating: not simply bringing the laboratory into the museum in order to free the Science Museum's curators from the charge of domesticating the Oramics Machine, but to ask whether we might also have underappreciated the domestic work of exhibition.

Received March $2^{\text {nd }} 2015$

Finally accepted November $11^{\text {th }} 2015$

\section{Acknowledgements:}

This research was funded by a 3-year grant from the Department of Sociology at Goldsmiths College. I would like to thank the curators at the Science Museum for accepting me as an ethnographer of their experiments, in particular Tim Boon. I would also like to thank Noortje Marres, Michael Guggenheim and Mike Michael who supervised the study.

\section{Notes}

1 The concept of 'quasi-objects', coined by the philosopher Michel Serres, was most broadly developed by Bruno Latour (1993b), one of the founders of actor-network theory. Latour argues that quasi-objects are: 'much more social are much more fabricated, much more collective than the 'hard' parts of nature, but they are in no way the arbitrary receptacles of a full-fledged society. On the other hand they are much more real, nonhuman and objective than those shapeless screens on which society - for unknown reasons - needed to be 'projected' (1993b: 55).

2 'Co-curating' was not the only concept used by the Museum's curators, but it is the one that I draw on here for the purposes of this discussion of curatorial work. Some of the groups participating groups are discussed below.

3 I discuss this point further below. As an amateur electronic musician I was able to join one of the groups with little difficulty; indeed, doing so unsettled distinctions between my own professional sociological commitments in the setting.

4 There are long standing debates among science museum professionals about the problems of displaying experimental practices 'in process' as well as their results (Durant 1992). 
5 In their staging of their works in the Science Museum's gallery the writers were explicitly gendered as a group.

\section{References}

Bennett, T., (2004) Pasts Beyond Memory: Evolution, Museums, Colonialism, London: Routledge.

(2005) 'Civic Laboratories', Cultural Studies, 19 (5) 521-47.

Callon, M., (1980) 'The State and Technical Innovation: A Case Study of the Electrical Vehicle in France', Research Policy, 9 (4) 358-76.

Callon, M., (1986) 'Some Elements of a Sociology of Translation: Domestication of the Scallops and the Fishermen', in J. Law, ed. Power, Action and Belief: A New Sociology of Knowledge, (Sociological Review Monograph 32), London: Routledge and Kegan Paul, 197-225.

Durant, J., (1992) Museums and the Public Understanding of Science, NMSI Trading Ltd.

Grierson, M. \& Boon, T., (2013) 'The Oramics Machine: The Lost Legacy of British Electronic and Computer Music?' in F. Weium \& T. Boon, (eds). Material Culture and Electronic Sound. Artefacts. Smithsonian Scholarly Press/Rowman \& Littlefield Publishers: Where?

Guggenheim, M., (2012) 'Laboratizing and De-Laboratizing the World: Changing Sociological Concepts for Places of Knowledge Production' History of the Human Sciences, 25 (1) 99-118.

Hacking, I., (1983) Representing and Intervening: Introductory Topics in the Philosophy of Natural Science, Cambridge: Cambridge University Press.

Haraway, D., (1984) 'Teddy Bear Patriarchy: Taxidermy in the Garden of Eden, New York City, 1908-1936' Social Text, (11) 20-64.

Harding, S. G., (1986) The Science Question in Feminism, Ithica \& London: Cornell University Press.

Hess, D.J., (2013) 'Neoliberalism and the History of STS Theory: Toward a Reflexive Sociology', Social Epistemology, 27 (2) 177-193.

Hetherington, K., (1999) 'From Blindness to blindness: Museums, Heterogeneity and the Subject'. In J. Law \& J. Hassard, eds. Actor Network Theory and After, Oxford, UK: Blackwell, 51-73.

Hooper-Greenhill, E., (1992) Museums and the Shaping of Knowledge, London: Routledge.

Knorr-Cetina, K., (1999) Epistemic Cultures: How the Sciences Make Knowledge, Cambridge Mass. \& London: Harvard University Press.

Kraeftner, B., Kroell, J. \& Warner, I., (2007) 'Walking on a Storyboard, Performing Shared Incompetence: Exhibiting "Science" in the Public Realm', in Sharon Macdonald \& P. Basu, eds. Exhibition Experiments, Oxford: Blackwell Publishing, 109-131.

Latour, B., (1996) Aramis, or, the Love of Technology, Location: Harvard University Press. (1999) 'Give Me a Laboratory and I Will Raise the World'. In M. Biagioli, ed. The Science Studies Reader, Hove: Psychology Press. 
(1988) Science in Action: How to Follow Scientists and Engineers through Society, Cambridge Mass. \& London: Harvard University Press.

(1993a) The Pasteurization of France, Location: Harvard University Press.

(1993b) We Have Never Been Modern, Location: Harvard University Press.

(2005) Reassembling the Social: An Introduction to Actor-Network-Theory, Oxford: Oxford University Press.

Latour, B. \& Woolgar, S., (1986) Laboratory Life: The Construction of Scientific Facts Location: Princeton University Press.

Lynch, M., (1985) Art and Artifact in Laboratory Science: A Study of Shop Work and Shop Talk in a Research Laboratory, London: Routledge \& Kegan Paul.

Macdonald, S., (2002) Behind the Scenes at the Science Museum, Oxford \& New York: Berg Publishers.

Macdonald, S. \& Basu, P., (eds) (2007) Exhibition Experiments Location: John Wiley \& Sons.

Macdonald, S. \& Silverstone, R., (1992) 'Science on Display: The Representation of Scientific Controversy' Museum Exhibitions. Public Understanding of Science, 1 (1) 69-87.

Morris, P., (2010) Science for the Nation: Perspectives on the History of the Science Museum Location: Palgrave Macmillan.

Shapin, S., (1988) 'The House of Experiment in Seventeenth-Century England' Isis, 79 (3) 373-404.

Shapin, S. \& Schaffer, S., (1985) Leviathan and the Air-Pump, Location: Princeton University Press.

Star, S.L. \& Griesemer, J., (1989) 'Institutional Ecology, Translations and Boundary Objects: Amateurs and Professionals in Berkeley's Museum of Vertebrate Zoology, 1907-39' Social Studies of Science, 19 (3) 387.

Waller, L., (2015) 'Rediscovering Daphne Oram's Home-Studio: Experiments Between Art, Technology and Domesticity' in I. Farias \& A. Wilkie, (eds). Studio Studies: Operations, Topologies, Displacements, London: Routledge.

Weibel, P. \& Latour, B., (2007) 'Experimenting with Representation: Iconoclash and Making Things Public', in S. MacDonald \& P. Basu, (eds.) Exhibition Experiments, 94-108 Oxford: Blackwell Publishing.

* Laurie Waller is a postdoctoral researcher at the Munich Centre for Technology In Society, at the Technische Universität München. His work addresses the social study of science and technology. He was previously a Lecturer at Goldsmiths, University of London.

Correspondence:

Munich Center for Technology in Society,

Arcisstraße 21,

80333 München

Email: I.waller@gold.ac.uk 